\title{
PREVALENCE OF ICAA AND ICAD GENES IN STAPHYLOCOCCUS AUREUS AND STAPHYLOCOCCUS EPIDERMIDIS STRAINS ISOLATED FROM PATIENTS AND HOSPITAL STAFF
}

\author{
Sara Elena Satorres, Lucía Esther Alcaráz \\ Department of Microbiology, National University, San Luis, Argentina
}

\begin{abstract}
SUMMARY
Staphylococci are ubiquitous microorganisms that predominate in normal skin and mucosal flora. Staphylococcus aureus and Staphylococcus epidermidis have been identified as a major cause of nosocomial infections, especially in patients with predisposing factors such as indwelling or implanted foreign bodies. The ability of both S. epidermidis and S. aureus to produce biofilm was compared between 116 clinically significant strains (46 from blood cultures of patients with bloodstream infection and 70 isolated from catheters) and 60 strains isolated from nasal swabs of healthy carriers from hospital staff. The presence of the intercellular adhesion genes (icaA and icaD) was determined by the Polymerase Chain Reaction method, and slime production was examined using qualitative Congo red agar technique. Among clinical strains, $35.2 \%$ (19/54) of $S$. aureus and $48.4 \%$ (30/62) of S.epidermidis were both positive icaA and icaD and they produced slime. Among carrier strains, $22.2 \%(8 / 36)$ of $S$. aureus and $33.3 \%$ (8/24) of S. epidermidis were positive for slime synthesis and exhibited ica genes. Our results suggest that the virulence factors contributing to the development of infections can be present in patient and hospital staff isolates. Thus, we consider it is important to detect healthy carriers of slime-producing staphylococci and to control the dissemination of these microorganisms especially in a hospital.
\end{abstract}

Key words: Staphylococcus aureus, Staphylococcus epidermidis, slime production, Congo red Agar, ica genes

Address for correspondence: S. E. Satorres, Area Microbiología, Universidad Nacional de San Luis, Chacabuco y Pedernera, 5700- San Luis, Argentina. E-mail: sasato@unsl.edu.ar

\section{INTRODUCTION}

Staphylococcus aureus and Staphylococcus epidermidis form part of the normal mucosal and skin microflora. Nasal carriers of staphylococci are recognized as important reservoir with the risk of developing endogenous infections or of transmitting infections to susceptible persons. S. aureus is one of the most frequently isolated bacterial pathogens causing both hospital and community-acquired infections and, together with S. epidermidis, is the organism most frequently isolated from medical implant-related infections. Several studies have been done to elucidate the mechanism by which Staphylococci are able to cause severe infections associated with biomaterials $(1,2,3)$. Certain S. aureus and S. epidermidis strains have the ability to colonize medical devices such as catheters and to develop a highly consolidated structure: the biofilm, which is believed to make the organisms more resistant to antibiotics and host defenses $(4,5,6,7)$. This is a serious complication, especially when the infection is caused by multiresistant bacteria difficult to eradicate from the prosthetic material.

The ability of bacteria to aggregate and form biofilm is strictly related to the capacity of producing an extracellular mucoid substance: the slime, whose main component is of polysaccharide nature and consists of glycosaminoglycans (8). It has been shown that both $S$. aureus and S. epidermidis contain the ica $(A D B C)$ operon responsible for slime production. In the operon, icaA encodes for $\mathrm{N}$-acetylglucosaminyltransferase, the enzyme for polysaccharide intercellular adhesin (PIA) synthesis $(9,10)$. However, the coexpression of icaA and icaD leads to significant increase in the activity and is related to the full phenotypic expression of the capsular polysaccharide (11). Several studies subsequently reported that the slime-producing strains of both $S$. aureus and S. epidermidis are more virulent and are responsible for intravenous catheters-related bacteremia and severe post-surgical or periprosthetic infections $(12,13,14,15)$.

The comparison between ica genes in S. epidermidis associated to either bacteremia or colonized intravenous devices and ica genes in S. epidermidis from normal flora of healthy volunteers who were not hospitalized showed that ica genes were twice more frequent in isolates associated to infection (16).

The aim of this study was to associate carriage and disease to the presence of icaA and icaD genes and slime production in both carrier and clinically significant strains. The present study was achieved by studying bacterial isolates collected from blood cultures, intravenous catheters and nasal mucosa of healthy volunteers from a regional hospital provided with 290 beds, in San Luis, Argentina. 


\section{MATERIALS AND METHODS}

Bacterial strains: Forty-six strains of Staphylococcus were obtained from blood of patients with non catheter-related bloodstream infections, 70 strains from intravenous catheters and 60 strains were isolated from nasal swabs of healthy care workers. The catheters from a localized infection revealed by signs of infection at the exit site, tunnel tract or pocket were analyzed. All isolates were grown in blood agar plates and mannitol salt agar for $24-48 \mathrm{~h}$ at $37^{\circ} \mathrm{C}$.

Species identification. Isolates were identified as S. aureus using Gram stain characteristics, traditional biochemical test, including catalase, coagulase, slide agglutination and acid production from glucose, D-maltose, D-trehalose, D-mannitol, sucrose. S. epidermidis was identified by a simplified method proposed by De Paulis et al. (17). Briefly, this five-test simple scheme combines the novobiocin susceptibility test with tests for urease, pyrrolidonyl arylamidase, ornithine decarboxylase, and aerobic acid from mannose. One or two tests within a particular species group were to be added to identify the isolate.

Control strains included two $S$. epidermidis reference strains, the ATCC 35984 slime-producing strain and the ATCC 12228 non slime-producing strain.

Detection of slime production. It was performed by using qualitative Congo red Agar (CRA) technique as previously described by Freeman et al. (18) with some modifications. Strains were streaked onto CRA plates ( $0.8 \mathrm{~g}$ of Congo red and $50 \mathrm{~g}$ of sucrose at 1 liter of brains heart infusion agar), incubated for $24 \mathrm{~h}$ at $37^{\circ} \mathrm{C}$ and subsequently overnight at room temperature. Plates were inspected for the color of the colonies at 24 and $48 \mathrm{~h}$. For colonies color evaluation, a four-color reference scale was used: black and bordeaux almost black as slime-producing strains, and bordeaux and red as non slime-producing strains.

The DNA extraction method has been previously described (19). A single colony of each bacterial strain was grown at $37^{\circ} \mathrm{C}$ for $24 \mathrm{~h}$ in trypticase soya broth. After incubation, the bacteria were harvested by centrifuging $100 \mu \mathrm{l}$ and resuspended in $50 \mu \mathrm{l}$ of lysostaphin solution $(100 \mu \mathrm{g} / \mathrm{ml})$, and samples were incubated at $37^{\circ} \mathrm{C}$. After $10 \mathrm{~min}, 50 \mu \mathrm{l}$ of proteinase $\mathrm{K}$ solution $(100 \mu \mathrm{g} / \mathrm{ml})$ and $150 \mu \mathrm{l}$ of $0,1 \mathrm{M}$ Tris- $\mathrm{HCl}(\mathrm{pH} 8)$ were added and incubated for a further $10 \mathrm{~min}$. Samples were then heated for $5 \mathrm{~min}$ at $100{ }^{\circ} \mathrm{C}$ and were centrifuged for $4 \mathrm{~min}$ at 5,000 $\mathrm{x}$. The DNA precipitate was resuspended in bidistilled water and used as a template for Polymerase Chain Reaction (PCR) method.
PCR method for the amplification of the icaA and icaD sequences: Two pairs of primers were designed for the amplification of the icaA and icaD genes with previously published sequences (19). For the detection of icaA, the following primers were used: 5'-ACAGTCGCTACGAAAAGAAA as the forward primer and $5^{\circ}$-GGAAATGCCATAATGACAAC as the reverse primer, yielding a PCR product of $103 \mathrm{bp}$. For the detection of icaD the following primers were used: 5 -ATGGTCAAGCCC AGACAGAG and 5'-CGTGTTTTCAACATTTAATGC AA as forward and reverse primer respectively, yielding a PCR product of $198 \mathrm{bp}$. PCR reactions were performed using the method described by Arciola et al. (19) with some modifications. The reaction mixture consisted of a reaction buffer $(50 \mathrm{mM} \mathrm{KCl}, 10$ $\mathrm{mM}$ Tris- $\mathrm{HCl}$ [pH 9], 2,5 $\mathrm{mM} \mathrm{MgCl}_{2}$ ) in a total volume of $25 \mu \mathrm{l}$ containing $5 \mu \mathrm{l}$ of template DNA (150 ng), 0,2 mM of each deoxynucleotide triphosphate (dATP, dTTP, dGTP, dCTP), 1 U Taq DNA polymerase and the above-mentioned primers $(0,4 \mu \mathrm{M}$ each for icaA and $1 \mu \mathrm{M}$ each for icaD). DNA amplification was carried out in a thermocycler with the following thermal cycling profile: initial denaturation at $94{ }^{\circ} \mathrm{C}$ for $5 \mathrm{~min}$, followed by 50 cycles of amplification (denaturation at $94{ }^{\circ} \mathrm{C}$ for $30 \mathrm{~s}$, annealing at $59^{\circ} \mathrm{C}$ for $30 \mathrm{~s}$ and extension at $72^{\circ} \mathrm{C}$ for $30 \mathrm{~s}$ ) ending with a final extension at $72{ }^{\circ} \mathrm{C}$ for $1 \mathrm{~min}$. After the first 30 cycles, a further $1 \mathrm{U}$ of Taq DNA polymerase was added.

Eight microliters of PCR products were analyzed by electrophoresis in $2 \%$ agarose gel during $50 \mathrm{~min}$ at $80 \mathrm{~V}$. The bands were stained with ethidium bromide $(0.5 \mu \mathrm{g} / \mathrm{ml})$ and observed under UV light. Each run included a DNA marker and the ATCC 12228 and ATCC 35984 S. epidermidis strains as controls.

\section{RESULTS}

The slime-production of all strains under study was performed by cultures on CRA. Slime-producing strains appear as black and bordeaux almost black colonies, and non slime-producing strains as bordeaux and red colonies (Fig. 1).

Among all the clinical isolates, 19 out of 54 S. aureus ( 9 from blood cultures and 10 from catheters) and 29 out of 62 S. epidermidis ( 6 from blood cultures and 23 from catheters) were found to be biofilm positive by CRA technique (Table 1).

The PCR technique was applied to the 176 staphylococcal strains (Table 1 and Fig. 2). All strains that were positive for icaA were also positive for icaD.

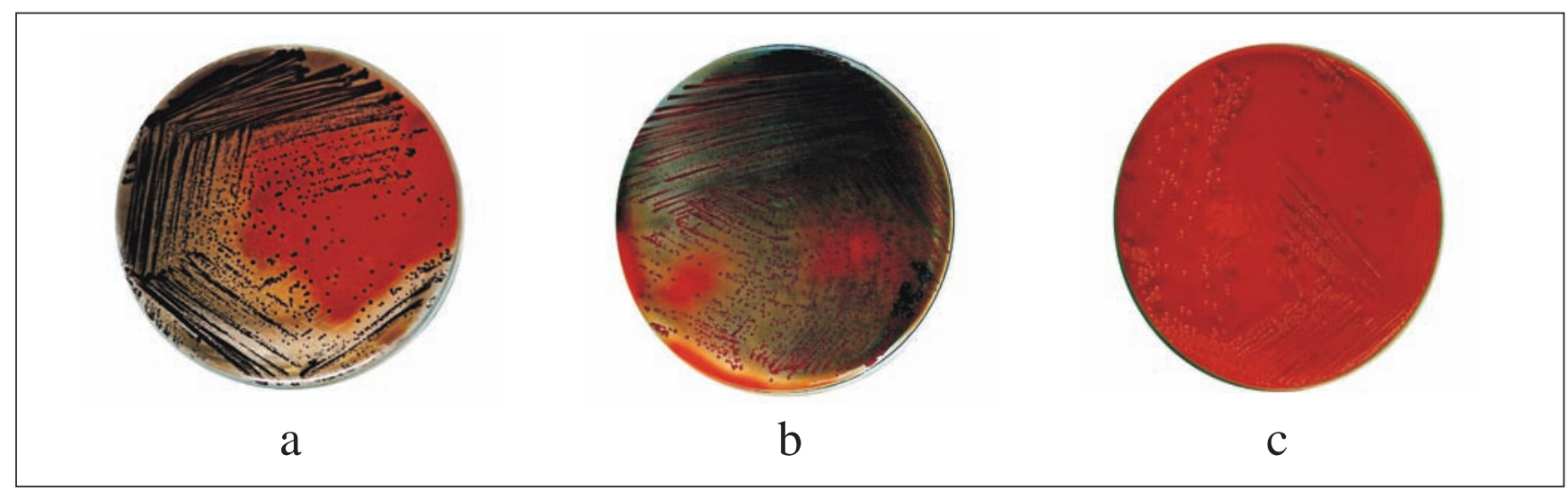

Fig. 1. Slime-production by cultures on CRA. a) Black colonies of slime producing S. epidermidis strain ATCC 35984. b) Bordeaux colonies of a non slime-producing strain. c) Red colonies of the non slime-producing S. epidermidis strain ATCC 12228. 
Table 1. Properties of blood culture and intravenous catheterisolated and hospital staff staphylococci

\begin{tabular}{|l|l|l|l|l|l|}
\hline & \multicolumn{5}{|c|}{ No. (\%) of isolates } \\
\hline $\begin{array}{l}\text { Type of isolates } \\
\text { (n) }\end{array}$ & $\begin{array}{l}\text { Presence of } \\
\text { ica genes }\end{array}$ & \multicolumn{3}{|c|}{ Colony morphology on CRA } \\
\hline & & Black & $\begin{array}{l}\text { Bordeaux } \\
\text { almost } \\
\text { black }\end{array}$ & Bordeaux & Red \\
\hline $\begin{array}{l}\text { Blood culture (46) } \\
\text { S. aureus (30) }\end{array}$ & $9(30)$ & $5(16.6)$ & $4(13.3)$ & $14(46.6)$ & $8(26.6)$ \\
S. epidermidis (16) & $6(37.5)$ & $4(25)$ & $2(12.5)$ & $4(25)$ & $6(37.5)$ \\
\hline $\begin{array}{l}\text { Catheter (70) } \\
\text { S. aureus (24) }\end{array}$ & $10(41.6)$ & $7(29.2)$ & $3(12.5)$ & $8(33.3)$ & $6(25)$ \\
S. epidermidis (46) & $24(52.1)$ & $15(32.6)$ & $8(17.4)$ & $12(26)^{1}$ & $11(24)$ \\
\hline $\begin{array}{l}\text { Hospital staff (60) } \\
\text { S. aureus (36) }\end{array}$ & $8(22.2)$ & $6(16.6)$ & $2(5.5)$ & $16(44.4)$ & $2(5.5)$ \\
S. epidermidis (24) & $8(33.3)$ & $7(29.2)$ & $1(4.2)$ & $10(41.7)$ & $6(25)$ \\
\hline
\end{tabular}

${ }^{1}$ One strain developed bordeaux colony and presented ica genes CRA: Congo red agar

Of all S. aureus and S. epidermidis strains isolated from blood cultured and catheters, 19/54 and 30/62 respectively were positive for the icaA and icaD genes. Only one strain of $S$. epidermidis was found to be non slime-producing by the CRA technique (Table 1).

Among the isolates from nasal mucosal of healthy volunteers, 8 out of 36 and 8 out of 24 S. aureus and S. epidermidis strains respectively were found to be slime-producing, and the ica genes were present.

\section{DISCUSSION}

S. epidermidis, together $S$. aureus, represents the most frequent cause of nosocomial sepsis, and they are the most common agents of infections associated with catheters and other indwelling medical devices. It is known that the capacity of staphylococci to adhere and grow on plastic surfaces is a crucial step in the pathogenesis of polymer-associated infections $(20,21)$. Moreover, biofilm production has also been shown to be associated with virulence in the absence of prosthetic material in an animal model (22).

In this study, the presence of ica genes and slime production was detected in $22.2 \%$ and $33.3 \%$ of $S$. aureus and S. epidermidis strains isolated from hospital staff respectively. Thus, it appears that the presence of ica genes and slime production are not exclusive characteristic of clinical Staphylococcus strains. These results are in agreement with those of Frebourg et al. (16), who found that the rate of strains carrying the ica locus among healthy volunteers was $37.5 \%$, but differ from those reported by other authors who have indicated the important role of ica genes as virulence markers for clinically significant Staphylococcus isolates $(11,23)$.

Arciola et al. (11) found that all saprophytic S. epidermidis strains from skin and mucosa were non slime-producing strains and ica genes were negative. However, in other studies, Ziebuhr et al. (23) and Arciola et al. (19) reported a $6 \%$ and $11.5 \%$, respectively, of saprophytic $S$. epidermidis strains isolated from hospi-

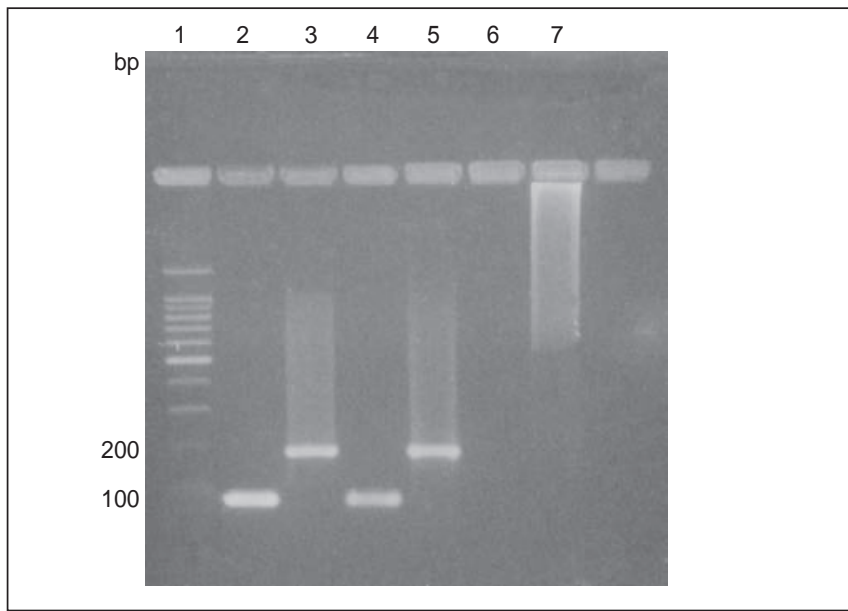

Fig. 2. PCR detection of icaA and icaD genes. Lane 1: molecular size marker; lane 2: 103-bp band obtained with DNA from slime producing S. epidermidis reference strain ATCC 35984 with primers for icaA; lane 3: 198-bp band obtained with DNA from slime producing $S$. epidermidis reference strain ATCC 35984 with primers for icaD; lane 4, 103-bp band obtained with DNA from slime producing $S$. epidermidis strain with primers for icaA; lane 5: 198-bp band obtained with DNA from slime producing S. epidermidis strain with primers for icaD; lane 6 and lane 7 : absence of bands with DNA fron non-slime producing S. epidermidis reference ATCC 12228 with primers for icaA and icaD respectively.

tal staff, which formed slime and exhibited positive ica genes. In our study, a higher percentage of these strains was detected. This leads us to think that the ica genes might be more prevalent in Staphylococcus strains isolated from the hospital staff than in those obtained from healthy individuals of a non-hospital community. Hospital staff is often colonized with nosocomial staphylococcal strains that could be the reason for increased proportion of ica positive strains in our study.

In agreement with other authors $(11,16,23)$, in the present study, the presence of ica genes was found to be more common in Staphylococcus strains associated with disease than in strains isolated from healthy carriers (Table 1).

In addition, a good correspondence between the phenotypic characterization by Congo red agar plate technique and ica genes presence was detected (Table 1). These data are in agreement with some authors $(11,23)$. However, Silva et al. (24), from blood culture isolates, reported that of the $49 \mathrm{~S}$. epidermidis strains found positive for the ica operon, only 29 (59\%) were found to be biofilm producers by the CRA technique.

Using PCR we detected icaA and icaD genes in 19 (35.2\%) clinical S. aureus strains isolated from catheters. Previous reports (11) detected these genes in 14 of $23(61 \%)$ isolates. On the other hand, Crampton et al. (9) and Fowle et al. (25) found all S. aureus isolates were ica $A D B C$ positive. A possible explanation for this discrepancy is that the primers used in our study were based on the icaAD sequence of RP62A S. epidermidis (GenBanK accession $\left.\mathrm{n}^{\circ} \mathrm{U} 43366\right)$ in which icaA and icaD display only $76 \%$ and $72 \%$ identity to the sequence of ATCC 35556 S. aureus respectively (9). 
In relation to $S$. epidermidis, $48.4 \%$ (30/62) of clinical strains present ica genes and only one of these strains was non-slime producing. Some authors suggest that the inactivation of ica operon occurs due to the insertion of the IS256 insertion sequence element $(3,23,26)$. The percentage of clinical slime-producing S. epidermidis strains found in the present study, is very close to that found by Arciola et al. (11) from catheters-associated infections whereas Zieburg et al. (23) reported that an $87 \%$ of S. epidermidis strains isolates from blood culture infections exhibits this characteristic.

The results reported here indicate that ica genes and slime production were not exclusive property of clinical Staphylococcus strains. This suggests that virulence factors can somehow be present in hospital staff strains and are not specific to clinical isolates only. We, in a previous study, detected slime-producing coagulase negative staphylococci environmental strains that were also resistant to oxacillin, from diverse surface and materials of the hospital rooms (27). For this reason we consider important the early and precise detection of slime producing Staphylococcus strains both in hospital environments and healthy carriers to control the dissemination of these microorganisms in a hospital community, especially among immunocompromised patients.

\section{Acknowledgments}

This work was supported by Department of Science and Technique of National University of San Luis, Argentina (Proj. 8802).

The authors thank Raúl Hasuoka for providing bacterial strains.

\section{REFERENCES}

1. An YH, Friedman RJ. Concise review of mechanisms of bacterial adhesion to biomaterial surfaces. J Biomed Mater Res. 1998;43(3):338-48.

2. Montanaro L, Arciola CR. Studying bacterial adhesion to irregular or porous surfaces. In: An YH, Friedman RJ, editors. Handbook of bacterial adhesion: principles, methods and applications. Totowa (NJ): Humana Press; 2000. p. 331-43.

3. Kiem S, Oh WS, Peck KR, Lee NY, Lee JY, Song JH, et al. Phase variation of biofilm formation in Staphylococcus aureus by IS256 insertion and its impact on the capacity adhering to polyurethane surface. J Korean Med Sci. 2004 Dec;19(6):779-82.

4. Donlan RM, Costerton JW. Biofilms: survival mechanisms of clinically relevant microorganisms. Clin Microbiol Rev. 2002 Apr;15(2):167-93.

5. Stewart PS, Costerton JW. Antibiotic resistance of bacteria in biofilms. Lancet. 2001 Jul 14;358(9276):135-8.

6. Mack D. Molecular mechanisms of Staphylococcus epidermidis biofilm formation. J Hosp Infect. 1999 Dec;43 Suppl:S113-25.

7. Rachid S, Ohlsen K, Witte W, Hacker J, Ziebuhr W. Effect of subinhibitory antibiotic concentrations on polysaccharide intercellular adhesin expression in biofilm-forming Staphylococcus aureus. Antimicrob Agents Chemother. 2000 Dec;44(12):3357-63.

8. Arciola CR, Campoccia D, Montanaro L. Detection of biofilm-forming strains of Staphylococcus epidermidis and S. aureus. Expert Rev Mol Diagn. 2002 Sep;2(5):478-84.

9. Cramton SE, Gerke C, Schnell NF, Nichols WW, Götz F. The intercellular adhesion (ica) locus is present in Staphylococcus aureus and is required for biofilm formation. Infect Immun. 1999 Oct;67(10):5427-33.
10. Gerke C, Kraft A, Sussmuth R, Schweitzer O, Götz F. Characterization of the $\mathrm{N}$-acetylglucosaminyltransferase activity involved in the biosynthesis of the Staphylococcus epidermidis polysaccharide intercellular adhesin. J Biol Chem. 1998 Jul 17;273(29):18586-93.

11. Arciola CR, Baldassarri L, Montanaro L. Presence of icaA and icaD genes and slime production in a collection of staphylococcal strains from catheter-associated infections. J Clin Microbiol. 2001 Jun;39(6):21516

12. Arciola CR, Collamati S, Donati E, Montanaro L. A rapid PCR method for the detection of slime-producing strains of Staphylococcus epidermidis and S. aureus in periprosthesis infections. Diagn Mol Pathol. 2001 Jun;10(2):130-7.

13. Davenport DS, Massanari RM, Pfaller MA, Bale MJ, Streed SA, Hierholzer WJ Jr. Usefulness of a test for slime production as a marker for clinically significant infections with coagulase-negative staphylococci. J Infect Dis. 1986 Feb;153(2):332-9.

14. Ishak MA, Groschel DH, Mandell GL, Wenzel RP. Association of slime with pathogenicity of coagulase-negative staphylococci causing nosocomial septicemia. J Clin Microbiol. 1985 Dec;22(6):1025-9.

15. Kotilainen P. Association of coagulase-negative staphylococcal slime production and adherence with the development and outcome of adult septicemias. J Clin Microbiol. 1990 Dec;28(12):2779-85.

16. Frebourg NB, Lefebvre S, Baert S, Lemeland JF. PCR-Based assay for discrimination between invasive and contaminating Staphylococcus epidermidis strains. J Clin Microbiol. 2000 Feb;38(2):877-80.

17. De Paulis AN, Predari SC, Chazarreta CD, Santoianni JE. Five-test simple scheme for species-level identification of clinically significant coagulasenegative staphylococci. J Clin Microbiol. 2003 Mar;41(3):1219-24.

18. Freeman DJ, Falkiner FR, Keane CT. New method for detecting slime production by coagulase-negative staphylococci. J Clin Pathol. 1989 Aug;42(8):872-4.

19. Arciola CR, Baldassarri L, Montanaro L. In catheter infections by Staphylococcus epidermidis the intercellular adhesion (ica) locus is a molecular marker of the virulent slime-producing strains. J Biomed Mater Res. 2002 Mar 5;59(3):557-62.

20. Christensen GD, Simpson WA, Bisno AL, Beachey EH. Adherence of slime-producing strains of Staphylococcus epidermidis to smooth surfaces. Infect Immun. 1982 Jul;37(1):318-26.

21. Peters G. Adherence of Staphylococcus epidermidis to plastic devices. J Med Microbiol. 1985;20(3):R2-R2.

22. Deighton MA, Borland R, Capstick JA. Virulence of Staphylococcus epidermidis in a mouse model: significance of extracellular slime. Epidemiol Infect. 1996 Oct;117(2):267-80.

23. Ziebuhr W, Heilmann C, Götz F, Meyer P, Wilms K, Straube E, et al. Detection of the intercellular adhesion gene cluster (ica) and phase variation in Staphylococcus epidermidis blood culture strains and mucosal isolates. Infect Immun. 1997 Mar;65(3):890-6.

24. de Silva GD, Kantzanou M, Justice A, Massey RC, Wilkinson AR, Day $\mathrm{NP}$, et al. The ica operon and biofilm production in coagulase-negative staphylococci associated with carriage and disease in a neonatal intensive care unit. J Clin Microbiol. 2002 Feb;40(2):382-8.

25. Fowler VG Jr, Fey PD, Reller LB, Chamis AL, Corey GR, Rupp ME. The intercellular adhesin locus ica is present in clinical isolates of Staphylococcus aureus from bacteremic patients with infected and uninfected prosthetic joints. Med Microbiol Immunol. 2001 Apr;189(3):127-31.

26. Cho SH, Naber K, Hacker J, Ziebuhr W. Detection of the icaADBC gene cluster and biofilm formation in Staphylococcus epidermidis isolates from catheter-related urinary tract infections. Int J Antimicrob Agents. 2002 Jun;19(6):570-5.

27. Alcaraz LE, Satorres SE, Lucero RM, de Centorbi ONP. Species identification, slime production and oxacillin susceptibility in coagulase-negative staphylococci isolated from nosocomial specimens. Braz J Microbiol. 2003 Jan-Apr;34(1):45-51.

Received in revised form and accepted February 21, 2007 